\title{
Monoclonality of Atypical Adenomatous Hyperplasia of the Lung
}

\author{
Seiji Niho, ${ }^{\star \dagger}$ Tomoyuki Yokose, ${ }^{\dagger}$ Kenji Suzuki, ${ }^{*}$ \\ Tetsuro Kodama, ${ }^{\ddagger}$ Yutaka Nishiwaki, ${ }^{*}$ and \\ Kiyoshi Mukai ${ }^{\dagger}$ \\ From the Division of Thoracic Oncology, "National Cancer \\ Center Hospital East, Pathology Division, ${ }^{\dagger}$ National Cancer \\ Center Research Institute East, and Division of Medicine, \\ National Cancer Center Hospital, Chiba, Japan
}

\begin{abstract}
Atypical adenomatous hyperplasia (AAH) of the lung has been postulated as a possible precursor lesion of bronchioloalveolar carcinoma (BAC). The clonality of AAHs from seven female patients was analyzed to determine whether AAH is a monoclonal expansion. All AAHs were identified in lungs surgically resected for BAC. The clonality of the BAC and bronchiolar metaplasia in each case was also analyzed. Approximately 500 cells in each lesion were precisely microdissected from methanol-fixed sections. Adjacent normal lung tissue was collected as a normal control. DNA was extracted for clonal analysis based on an X-chromosome-linked polymorphic marker, the human androgen receptor gene (HUMARA). HUMARA was found to be amplified with or without previous digestion by the methylation-sensitive restriction endonuclease Hpa II. Five cases were informative. All 10 AAHs and 7 BACs obtained from the informative cases showed monoclonality, whereas the control cells showed polyclonality. Three different AAH lesions in a single case showed both possible patterns of monoclonality. BAC and contiguous AAH showed identical monoclonality in two cases. Two lesions of bronchiolar metaplasia, which was considered reactive, were polyclonal. Our results demonstrated the monoclonal nature of $\mathrm{AAH}$, and this finding suggests that $\mathrm{AAH}$ is a precursor of BAC or a preneoplastic condition. (Am J Patbol 1999, 154:249-254)
\end{abstract}

Pulmonary adenocarcinoma is now one of the most common types of lung cancer. Unlike squamous cell carcinoma of the lung, in which precursor lesions have been identified, ${ }^{1-3}$ the preneoplastic lesion of adenocarcinoma remains undefined. Bronchioloalveolar carcinoma (BAC) is a subset of pulmonary adenocarcinoma and contains three histological types: mucinous, nonmucinous, and sclerosing. ${ }^{4}$ Recently, atypical adenomatous hyperplasia $(\mathrm{AAH})$ has been postulated as a possible precursor of BAC, and many studies have been conducted to char- acterize $\mathrm{AAH}{ }^{5-14}$ Cytofluorometric analyses have showed that the DNA histogram patterns of $\mathrm{AAH}$ are intermediate between those of reactive hyperplasia of type II pneumocytes and small-sized well differentiated adenocarcinomas and that $\mathrm{AAH}$ is a clonal cellular proliferation closely related to well differentiated adenocarcinoma. ${ }^{15}$ An image cytometric analysis also showed that some cases of AAH displayed aneuploid histogram patterns. ${ }^{16}$ Several genetic analyses of $\mathrm{AAH}$ revealed that $15 \%$ to $39 \%$ of $\mathrm{AAH}$ s had K-ras mutations. ${ }^{17,18}$ Immunohistochemical analyses of p53 and c-erbB-2 have indicated that $\mathrm{AAH}$ exhibits certain genetic changes associated with malignancy. ${ }^{7,19}$ However, $\mathrm{AAH}$ for telomerase activity has been found to be negative by radioactive in situ hybridization. ${ }^{20}$ Although evidence has been accumulated that $\mathrm{AAH}$ is a precursor of $\mathrm{BAC}$, its preneoplastic or neoplastic character has not been definitely proven.

Monoclonality has been thought to be a fundamental characteristic of neoplasia. ${ }^{21,22}$ One $X$ chromosome is randomly and permanently inactivated at an early stage of embryogenesis in the female. This leads to somatic mosaicism of normal females with respect to X-linked alleles, with approximately one-half of the somatic cells expressing the maternal allele and the other half expressing the paternal allele. Tumors arising from a single cell will therefore express one of the two phenotypes. Recently, a highly polymorphic trinucleotide CAG repeat in the $\mathrm{X}$-linked human androgen receptor gene (HUMARA) has been used to distinguish between the two $X$ chromosomes $^{23}$ and detect monoclonality in various neoplastic diseases, ${ }^{24-29}$ including BAC. ${ }^{30}$

Bronchiolar metaplasia (or alveolar bronchiolization) may be observed after a variety of insults, such as respiratory infection, exposure to chemical irritants, carcinogens, and circulatory disturbances involving the lung. ${ }^{31}$ Bronchiolar metaplasia simulates BAC morphologically because the metaplastic epithelial cells proliferate along the alveolar wall ${ }^{32}$; however, it has been considered reactive, not neoplastic, because the epithelial cells do not show atypia.

Supported in part by a grant from the Ministry of Health and Welfare for the Second-term Comprehensive Strategy for Cancer Control and a grant-in aid for cancer research from the Ministry of Health and Welfare, Japan.

Accepted for publication September 17, 1998.

K. Mukai's current address: First Department of Pathology, Tokyo Medical University, Tokyo, Japan.

Address reprint requests to Dr. Seiji Niho, the Division of Thoracic Oncology, National Cancer Center Hospital East, 6-5-1, Kashiwanoha, Kashiwa, Chiba 277-8577, Japan. E-mail: siniho@east.ncc.go.jp. 
The aim of this study was to determine 1) whether $\mathrm{AAH}$ is a monoclonal expansion, 2) whether the clonality of $\mathrm{AAH}$ is consistent with that of BAC when $\mathrm{AAH}$ is contiguous to BAC, and 3) whether other peripheral pulmonary lesions such as bronchiolar metaplasia are monoclonal or polyclonal expansions.

\section{Materials and Methods}

\section{Patients}

Sixty-nine patients underwent resection of the lung because of cancer at the National Cancer Center Hospital East from September 1997 to January 1998. Among them, 21 patients (30\%) had concomitant AAH. Eight were male and thirteen were female. Seven female cases in which we found $\mathrm{AAH}$ s or bronchiolar metaplasia were available for the analysis of the clonality. All AAHs were identified in lungs surgically resected for BAC. The locations in which samples were taken were assigned by gross dissection.

\section{Histological Criteria for AAH, Bronchiolar Metaplasia, and BAC}

The histological diagnosis of AAH was made based on the following criteria, as previously described ${ }^{6,8,9,16,33}: 1$ ) the lesion is localized with well defined boundaries; 2) atypical cuboidal to low columnar or peg-shaped cells, resembling either type II pneumocytes or Clara cells, have proliferated along the slightly thickened alveolar wall, and mild inflammatory infiltration may be present without scar formation; and 3) atypical cells in $\mathrm{AAH}$ have variable degrees of nuclear atypia, but it is less prominent than in adenocarcinoma (Figure 1). Bronchiolar metaplasia is characterized by the presence of ciliated columnar cells extending from the bronchus to the alveoli without atypia (Figure 2). BAC is defined as pulmonary adenocarcinomas in which most of the tumor grows as a single cell layer along alveolar walls, forming apparent glands of uniform size. ${ }^{4}$

\section{Strategy for Clonal Analysis}

We conducted clonal analysis according to the method of Allen et al. ${ }^{23}$ The strategy is based on random $X$ chromosome inactivation by methylation. This random inactivation occurs early in embryogenesis and remains conserved throughout cell division, even in tumors. The HUMARA on the $\mathrm{X}$ chromosome has a trinucleotide (CAG) repeat polymorphism. We used Hpall, which cannot digest methylated DNA, to cut DNA before polymerase chain reaction (PCR), so that only the methylated allele was amplified. If the methylation pattern is uniform because of monoclonality, there is only one PCR product after Hpall digestion, whereas if the methylation patterns differ (polyclonal), two PCR products are obtained for the trinucleotide repeat polymorphism. The HUMARA polymorphism results were compared with the normal sample
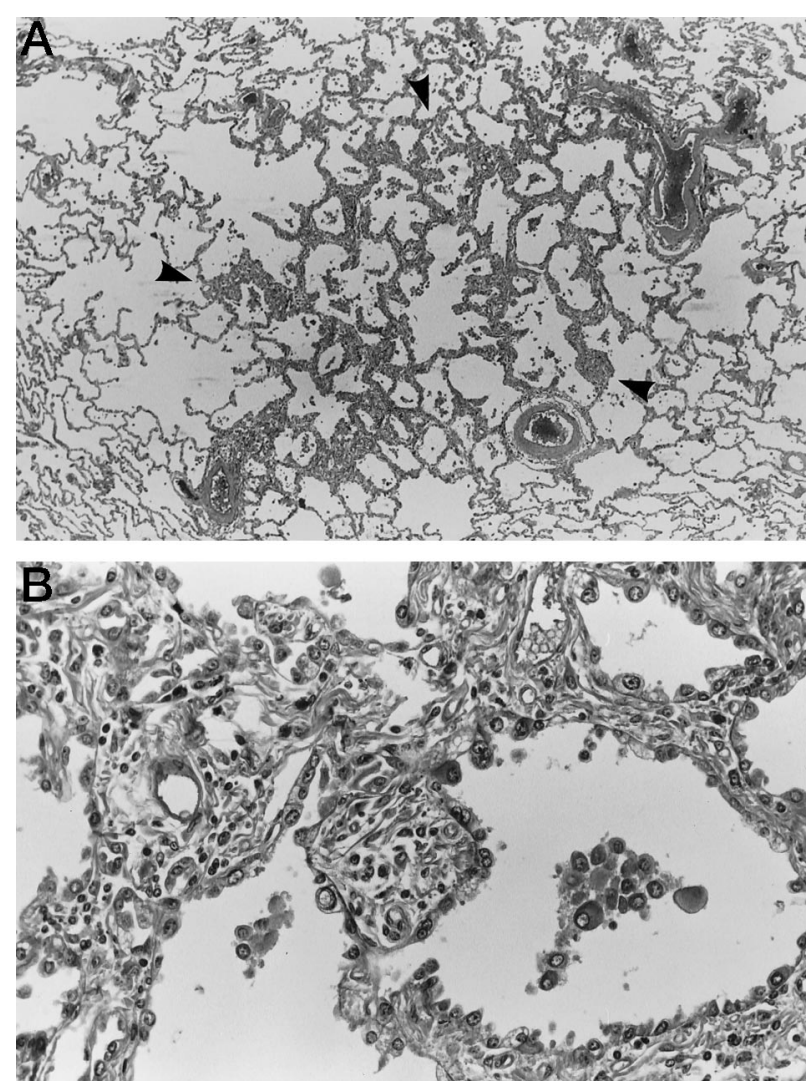

Figure 1. Representative histopathological findings of atypical adenomatous hyperplasia (AAH) of the lung in case 2 (AAH 2-2). The lesion is localized and has well defined boundaries (A). Atypical cuboidal cells have proliferated along the slightly thickened alveolar wall. The epithelial cells of AAH have a round nucleus with a prominent nucleolus (B). H\&E; original magnification, $\times 30(\mathrm{~A})$ and $\times 256(\mathrm{~B})$

used in the study. In monoclonal cases, if the longer or shorter allele is amplified after Hpall digestion, we refer to it as the / or $s$ pattern of monoclonality, respectively.

\section{DNA Extraction}

The resected lungs were fixed with $100 \%$ methanol and embedded in paraffin. The paraffin blocks containing the $\mathrm{BAC}, \mathrm{AAH}$, or bronchiolar metaplasia that was found in routine pathological studies were cut into $5-\mu \mathrm{m}$ sections and stained with hematoxylin and eosin (H\&E). Approximately 500 cells were microdissected under a microscope (BX50W1, Olympus, Tokyo, Japan) by using a microcapillary tube drawn to a thin tip with a micropipette puller (PC-10, Narishige, Tokyo, Japan) and a joystickoperated hydraulic micromanipulator (ONO-125, Olympus-Narishige, Tokyo, Japan) (Figure 3). The microdissected cells were allowed to adhere to Parafilm (American Can, Greenwich, CT) and placed into 500- $\mu$ l microcentrifuge tubes. Adjacent normal lung tissue was scraped with a 27-gauge needle to provide a normal control. DNA was extracted with the DNA extractor WB kit (Wako Pure Chemicals, Osaka, Japan). 


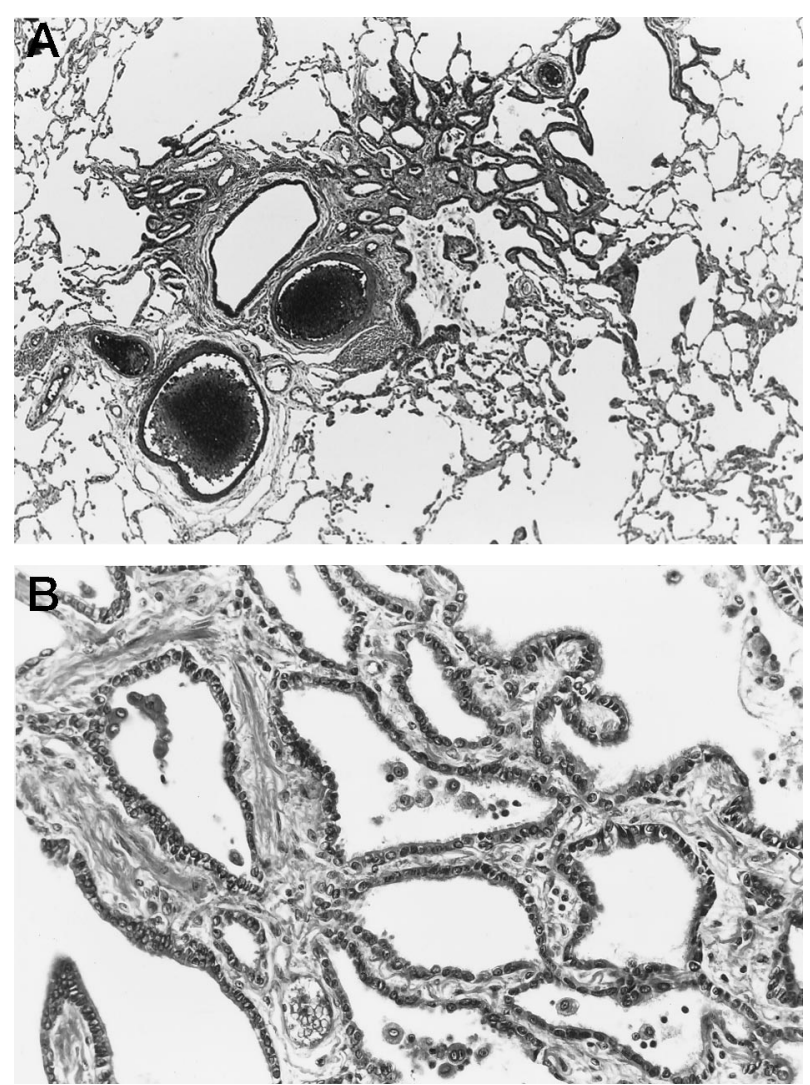

Figure 2. Representative histopathological findings of bronchiolar metaplasia. Ciliated columnar cells have extended from the bronchus to the alveoli without atypia. H\&E; original magnification, $\times 38$ (A) and $\times 206$ (B)

\section{Polymerase Chain Reaction}

DNA was digested with Rsal and with or without Hpall, and the HUMARA was then amplified by PCR as previously described. ${ }^{34}$ Amplification of the HUMARA in exon 1 was performed using primers AR1 and AR2, essentially as described by Mutter et $\mathrm{al}^{35}$ with slight modifications. Six percent (w/v) of dimethylsulfoxide and dGTP instead of 7-deaza-2'-dGTP were added. AR2 was labeled at the $3^{\prime}$ end with fluorescein. The HUMARA PCR products were analyzed with an automatic sequencer (ALFred, Pharmacia, Uppsala, Sweden) and quantified with the Fragment Manager software package (Pharmacia).

\section{Results}

The characteristics of the cases are summarized in Table 1. Patient 1 had $28 \mathrm{AAHs}$, patient 2 had three, patient 7 had two, patient 3 had one, and patient 4 had one in the periphery of BAC. Patient 5 had three AAHs, one of which was located at the borders of the BAC. Patients 4 and 7 also had foci of bronchiolar metaplasia apart from the BAC. Patient 5 had three BACs in the right upper and middle lobes (in the S3ai, S3aii, and S4a).

Five of the seven cases were informative, with two PCR products of HUMARA ( $s$ and $/$ ) in the normal control. All 10 AAHs analyzed and seven BACs showed a monoclonal pattern, whereas two foci of bronchial metaplasia and
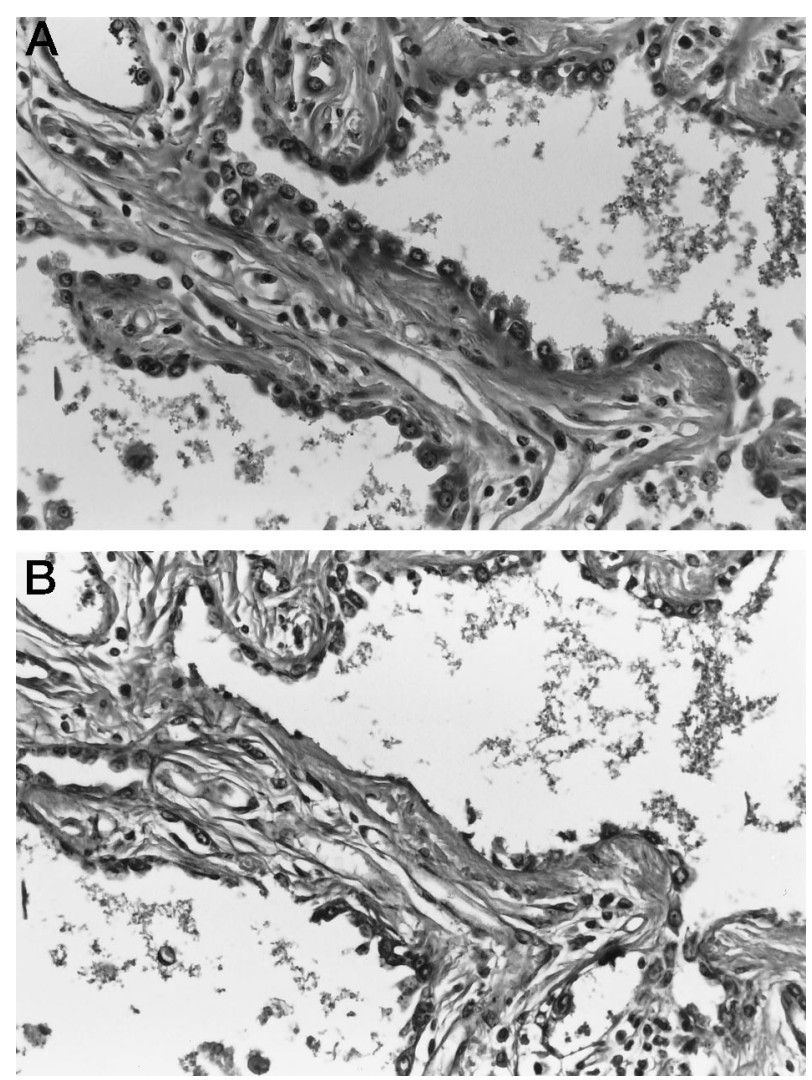

Figure 3. Precise microdissection. AAH cells (A) were microdissected out to prepare DNA extraction (B). H\&E; original magnification, $\times 300$.

normal lung showed a polyclonal pattern (Table 1). In cases 2 and 5, different foci of AAHs from individual patients showed both possible patterns of monoclonality, which meant some retained the shorter allele ( $s$ pattern of monoclonality) and others the longer allele (I pattern of monoclonality) (Figure 4A).

Furthermore, in case 5, two BACs in the upper lobe showed the $s$ pattern of monoclonality, whereas a BAC in the middle lobe showed the / pattern of monoclonality. Monoclonality was also seen in the AAH located at the periphery of BAC, and its pattern was identical to that of $\mathrm{BAC}$ in cases 4 and 5 (Figure 4B).

\section{Discussion}

Several molecular analyses of $\mathrm{AAH}$ have been reported, including analyses for K-ras mutation ${ }^{17,18}$ and telomerase activity. ${ }^{20}$ Although it has not yet been determined whether $\mathrm{AAH}$ is a precursor lesion of $\mathrm{BAC}$, evidence has been accumulating in support of the hypothesis that $\mathrm{AAH}$ is a preneoplastic lesion of BAC. In the present study, we clearly demonstrated monoclonal expansion of $\mathrm{AAH}$ on the basis of random $\mathrm{X}$-chromosome inactivation.

Monoclonality of various tumors has been reported, including myeloproliferative disorders, ${ }^{24}$ leiomyoma, Wilms' tumor, ${ }^{25}$ Hodgkin's disease, ${ }^{26}$ gynecological cancer, ${ }^{27}$ and multiple cancer of bladder $^{28}$ and breast. ${ }^{36}$ However, Murry et $\mathrm{al}^{37}$ have recently showed monoclonality of smooth muscle cells in human atherosclero- 
Table 1. Clinical Features and Clonal Results

\begin{tabular}{|c|c|c|c|c|c|}
\hline Case & Age (years) & Size (mm) & Location* & Lesion & HUMARA \\
\hline 2 & 58 & $\begin{aligned} 16 & \times 14 \times 12 \\
2 & \times 1.5 \\
3 & \times 2.5 \\
3 & \times 3\end{aligned}$ & $\begin{array}{l}\text { S6b } \\
\text { S10a } \\
\text { S10a } \\
\text { S10c }\end{array}$ & $\begin{array}{l}\text { BAC } 2 \\
\text { AAH 2-1 } \\
\text { AAH 2-2 } \\
\text { AAH 2-3 } \\
\text { NL }\end{array}$ & $\begin{array}{l}\text { Monoclonal (I) } \\
\text { Monoclonal (I) } \\
\text { Monoclonal (I) } \\
\text { Monoclonal (s) } \\
\text { Polyclonal }\end{array}$ \\
\hline 3 & 72 & $\begin{array}{l}25 \times 25 \times 10 \\
10 \times 10\end{array}$ & $\begin{array}{l}\text { S3a } \\
\text { S1a }\end{array}$ & $\begin{array}{l}\text { BAC } 3 \\
\text { AAH } 3 \\
\text { NL }\end{array}$ & $\begin{array}{l}\text { Monoclonal (s) } \\
\text { Monoclonal (s) } \\
\text { Polyclonal }\end{array}$ \\
\hline 4 & 72 & $\begin{array}{l}15 \times 14 \times 8 \\
1.5 \times 1\end{array}$ & $\begin{array}{l}\text { S6c at periphery of BAC } 4 \\
\text { S10 }\end{array}$ & $\begin{array}{l}\text { BAC } 4 \\
\text { AAH } 4 \\
\text { BM } \\
\text { NL }\end{array}$ & $\begin{array}{l}\text { Monoclonal (s) } \\
\text { Monoclonal (s) } \\
\text { Polyclonal } \\
\text { Polyclonal }\end{array}$ \\
\hline 5 & 60 & $\begin{array}{l}14 \times 8 \times 8 \\
5 \times 3 \\
4 \times 3 \\
2 \times 1 \\
5 \times 3\end{array}$ & $\begin{array}{l}\text { S3ai at periphery of BAC 5-1 } \\
\qquad \begin{array}{c}\text { S4a } \\
\text { S3aii } \\
\text { S3a } \\
\text { S3bi }\end{array}\end{array}$ & $\begin{array}{l}\text { BAC 5-1 } \\
\text { AAH 5-1 } \\
\text { BAC 5-2 } \\
\text { BAC 5-3 } \\
\text { AAH 5-2 } \\
\text { AAH 5-3 } \\
\text { NL }\end{array}$ & $\begin{array}{l}\text { Monoclonal (s) } \\
\text { Monoclonal (s) } \\
\text { Monoclonal (I) } \\
\text { Monoclonal (s) } \\
\text { Monoclonal (I) } \\
\text { Monoclonal (I) } \\
\text { Polyclonal }\end{array}$ \\
\hline 7 & 51 & $\begin{aligned} 32 & \times 31 \times 21 \\
5 & \times 4 \\
1.5 & \times 1 \\
2 & \times 1\end{aligned}$ & $\begin{array}{l}\text { S8 } \\
\text { S9b } \\
\text { S9b } \\
\text { S8 }\end{array}$ & $\begin{array}{l}\text { BAC } 7 \\
\text { AAH 7-1 } \\
\text { AAH 7-2 } \\
\text { BM } \\
\text { NL }\end{array}$ & $\begin{array}{l}\text { Monoclonal (s) } \\
\text { Monoclonal (I) } \\
\text { Monoclonal (I) } \\
\text { Polyclonal } \\
\text { Polyclonal }\end{array}$ \\
\hline
\end{tabular}

Cases 1 and 6 were homozygous for a trinucleotide repeat in the androgen receptor gene on the $X$ chromosome and thus uninformative for the analysis. BAC, bronchioloalveolar carcinoma; AAH, atypical adenomatous hyperplasia; NL, normal lung; s, shorter-allele-inactivated pattern; I, longerallele-inactivated pattern; BM, bronchiolar metaplasia.

*Locations assigned by gross dissection.

sis, which is considered a non-neoplastic lesion. Nomura et $\mathrm{al}^{34}$ showed monoclonality of each pyloric gland in the stomach. These findings suggested three possible explanations for the monoclonality of $A A H: 1)$ the size of patches (groups of cells with the same patterns of $X$ chromosome inactivation) in the alveolar epithelium was larger than the lesions investigated; 2) a single cell in a heterogeneous lesion responded to a growth stimulation and proliferated overwhelmingly; or 3) a single cell underwent transformation into a neoplasm. The patch size of normal alveolar cells has remained undetermined. The normal control in our study was polyclonal, because it contained not only alveolar cells but several capillary cells or interstitial cells. However, dissected metaplastic epithelium (bronchiolar metaplasia), which has been considered to be a reactive hyperplastic lesion, was found to be polyclonal in our study. The size of the area in which the cells were microdissected was similar for both bronchiolar metaplasia and $\mathrm{AAH}$. Therefore, it is reasonable to conclude that the size of $\mathrm{AAH}$ was greater than the patch size. Clonal expansion of the cells carrying alterations of oncogenes and/or tumor suppressor genes defines neoplasia at a fundamental genetic level. ${ }^{17}$ Taken together, our present findings and previous reports of K-ras mutation in $\mathrm{AAH}^{17,18}$ led us to conclude that $\mathrm{AAH}$ is neoplastic and not reactive or hyperplastic.

Multiple AAHs have been found occasionally. ${ }^{19} \mathrm{AAH}$ has never been thought to disseminate because $A A H$ cells do not invade the pulmonary mesenchyme histopathologically. In our study, AAH 2-3 showed an / pattern of monoclonality, whereas AAH 2-1 and 2-2 showed an $s$ pattern. These findings indicate that multiple AAHs are of multicentric origin and that each grows independently.

$\mathrm{AAH}$ is frequently seen at the borders of BAC as in cases 4 and 5, whose $A A H$ and BAC showed the identical pattern of monoclonality. If $B A C$ originates from $A A H$, their monoclonality should be identical. The possibility of the BAC and $A A H$ at its borders in these two cases occurring by chance is $25 \%$, even if independent lesions; therefore, clonal analysis of many cases is necessary to establish the relationship between $\mathrm{AAH}$ and BAC. ${ }^{5-12}$

Case 5 had three BACs in the right upper and middle lobes, and these BACs showed both possible patterns of monoclonality. This finding indicated that the middle lobe tumor was not a metastasis from the upper lobe tumors, but a multicentric primary tumor. Clonal analysis based on X-chromosome inactivation is one of the most useful methods of differentiating between multiple and metastatic cancers when the histological type of multiple tumors is similar, especially in gynecological or breast cancer. $^{36,38}$ The ability to diagnose multiple primary or metastatic lung cancer by this method is limited, because 1) male cases cannot be analyzed; 2) $10 \%$ to $20 \%$ of female cases are not informative for homozygosity in the HUMARA polymorphic site; and 3) there is a $50 \%$ probability of identical $\mathrm{X}$-chromosome inactivation occurring in two tumors even if their clonality is different. Noguchi et $\mathrm{al}^{39}$ showed that the p53 gene mutation pattern is an effective marker for diagnosis of tumor multiplicity. Therefore, a combination of clonal analysis and p53 mutation analysis would have a greater impact on the diagnosis of multiple cancer than either one of the two methods alone. 
A

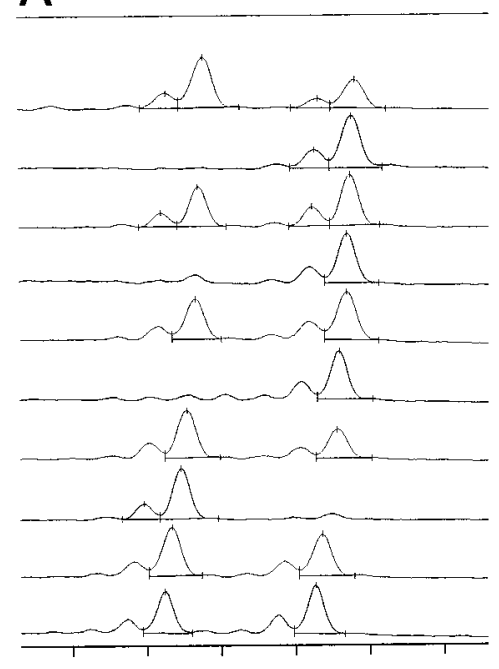

HpaII

$(-)$

(+) $]$ BAC 2

$\left.\begin{array}{l}(-) \\ (+)\end{array}\right]$ AAH 2-1

$(-)$

(+) ] АAH 2-2

$(-)]$ AAH 2-3

$\left.\begin{array}{l}(-) \\ (+)\end{array}\right] \mathrm{NL}$

B

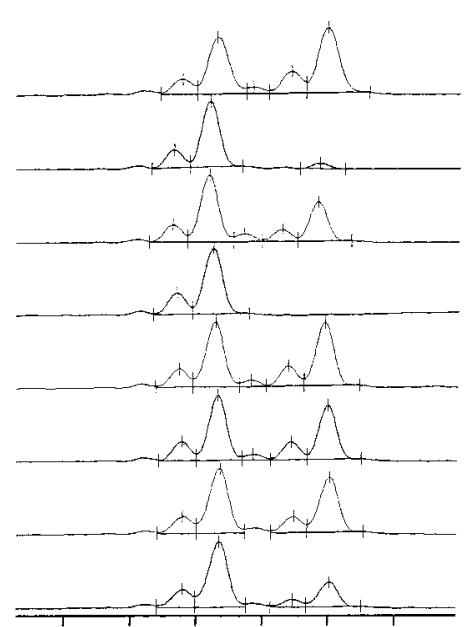

HpaII

$\left.\begin{array}{l}(-) \\ (+)\end{array}\right]$ BAC 4

$(-)$

$(+)$

AAH 4

$\left.\begin{array}{l}(-) \\ (+)\end{array}\right] \mathbf{B M}$

$\left.\begin{array}{l}(-) \\ (+)\end{array}\right] \mathrm{NL}$

Figure 4. Clonal analysis by amplification of the human androgen receptor gene with or without $H p a I$ I digestion in case 2 (A) and case 4 (B). BAC 2 and AAH 2-1 and 2 showed the $l$ pattern of monoclonality, whereas AAH 2-3 showed the $s$ pattern (A). AAH 4 located at the periphery of BAC 4 showed the $s$ pattern of monoclonality, identical to that of BAC 4 (B). In contrast, bronchiolar metaplasia and normal lung showed a polyclonal pattern. BAC, bronchioloalveolar carcinoma; AAH, atypical adenomatous hyperplasia; NL, normal lung; BM, bronchiolar metaplasia.

Genetic analysis of $\mathrm{AAH}$ used to be difficult, because AAHs are such small lesions and most of them are found incidentally during routine pathological examinations. In addition, whole-lung fixation with formalin makes it difficult to extract DNA and perform PCR on such small lesions as $\mathrm{AAH}$. Fixation with methanol, however, can circumvent this problem because it is an excellent method for both DNA and morphological analyses. ${ }^{40}$ Furthermore, our precise microdissection method makes it possible to genetically analyze small lesions such as $\mathrm{AAH}$.

In conclusion, $\mathrm{AAH}$ exhibited a monoclonal expansion of epithelial cells, whereas reactive lesions such as bronchiolar metaplasia showed polyclonality. Considering the fact that K-ras activation was reported previously in $\mathrm{AAH}$, our findings strongly support the idea that $A A H$ is a preneoplastic lesion rather than reactive hyperplasia. Our findings also supported the possibility of an adenomacarcinoma sequence in lung carcinogenesis, based on the discovery of identical monoclonal patterns in BAC and $\mathrm{AAH}$ peripheral to it. Additional molecular analyses are necessary to further characterize the biological nature of $\mathrm{AAH}$.

\section{Acknowledgments}

We thank Professor Michio Yamakido, The Second Department of Internal Medicine, Hiroshima University School of Medicine, Hiroshima, Japan, for his encouragement during this study.

\section{References}

1. Auerbach O, Saccomanno G, Kuschner M, Brown RD, Garfinkel L: Histological findings in the tracheobronchial tree of uranium miners and non-miners with lung cancer. Cancer 1978, 42:483-489

2. Carter D: Pathology of early squamous cell carcinoma of the lung. Pathol Annu 1978, 13:131-147

3. Saccomanno G, Archer VE, Auerbach O, Saunders RP, Brennan LM: Development of carcinoma of the lung as reflected in exfoliated cells. Cancer 1974, 33:256-270

4. Clayton F: The spectrum and significance of bronchioloalveolar carcinomas. Pathol Annu 1988, 23:361-394

5. Carey FA, Wallace WA, Fergusson RJ, Kerr KM, Lamb D: Alveolar atypical hyperplasia in association with primary pulmonary adenocarcinoma: a clinicopathological study of 10 cases. Thorax 1992, 47:1041-1043

6. Colby TV, Koss MN, Travis WD. Bronchioloalveolar carcinoma. Atlas of Tumor Pathology: Tumors of the Lower Respiratory Tract, 3rd series, Fasc. 13. Washington DC, Armed Forces Institute of Pathology, 1995, pp 203-234

7. Kerr KM, Carey FA, King G, Lamb D: Atypical alveolar hyperplasia: relationship with pulmonary adenocarcinoma, p53, and c-erbB-2 expression. J Pathol 1994, 174:249-256

8. Miller RR: Bronchioloalveolar cell adenomas. Am J Surg Pathol 1990, 14:904-912

9. Mori M, Chiba R, Takahashi T: Atypical adenomatous hyperplasia of the lung and its differentiation from adenocarcinoma: characterization of atypical cells by morphometry and multivariate cluster analysis. Cancer 1993, 72:2331-2340

10. Mori M, Tezuka F, Chiba R, Funae Y, Watanabe M, Nukiwa T, Takahashi T: Atypical adenomatous hyperplasia and adenocarcinoma of the human lung: their heterology in form and analogy in immunohistochemical characteristics. Cancer 1996, 77:665-674

11. Rao SK, Fraire AE: Alveolar cell hyperplasia in association with adenocarcinoma of lung. Mod Pathol 1995, 8:165-169

12. Shimosato $Y$, Noguchi M, Matsuno $Y$ : Adenocarcinoma of the lung: its development and malignant progression. Lung Cancer 1993, 9:99-108

13. Suzuki K, Nagai K, Yoshida J, Yokose T, Kodama T, Takahashi K, Nishimura M, Kawasaki H, Yokozaki M, Nishiwaki Y: The prognosis of resected lung carcinoma associated with atypical adenomatous hyperplasia: a comparison of the prognosis of well-differentiated adenocarcinoma associated with atypical adenomatous hyperplasia and intrapulmonary metastasis. Cancer 1997, 79:1521-1526

14. Suzuki K, Takahashi K, Yoshida J, Nishimura M, Yokose T, Nishiwaki Y, Nagai K: Synchronous double primary lung carcinomas associated with multiple atypical adenomatous hyperplasia. Lung Cancer 1998, 19:131-139

15. Nakayama $H$, Noguchi M, Tsuchiya R, Kodama T, Shimosato $Y$ : Clonal growth of atypical adenomatous hyperplasia of the lung: cytofluorometric analysis of nuclear DNA content. Mod Pathol 1990, 3:314-320

16. Yokozaki M, Kodama T, Yokose T, Matsumoto T, Mukai K: Differenti- 
ation of atypical adenomatous hyperplasia and adenocarcinoma of the lung by use of DNA ploidy and morphometric analysis. Mod Pathol 1996, 9:1156-1164

17. Westra WH, Baas IO, Hruban RH, Askin FB, Wilson K, Offerhaus GJ, Slebos RJ: K-ras oncogene activation in atypical alveolar hyperplasias of the human lung. Cancer Res 1996, 56:2224-2228

18. Cooper CA, Carby FA, Bubb VJ, Lamb D, Kerr KM, Wyllie AH: The pattern of K-ras mutation in pulmonary adenocarcinoma defines a new pathway of tumour development in the human lung. J Pathol 1997, 181:401-404

19. Kitamura H, Kameda $Y$, Nakamura N, Nakatani $Y$, Inayama $Y$, lida M, Noda K, Ogawa N, Shibagaki T, Kanisawa M: Proliferative potential and p53 overexpression in precursor and early stage lesions of bronchioloalveolar lung carcinoma. Am J Pathol 1995, 146:876-887

20. Yashima K, Litzky LA, Kaiser L, Rogers T, Lam S, Wistuba II, Milchgrub S, Srivastava S, Piatyszek MA, Shay JW, Gazdar AF: Telomerase expression in respiratory epithelium during the multistage pathogenesis of lung carcinomas. Cancer Res 1997, 57:2373-2377

21. Fialkow PJ: Clonal origin of human tumors. Biochim Biophys Acta 1976, 458:283-321

22. Nowell PC: The clonal evolution of tumor cell populations. Science 1976, 194:23-28

23. Allen RC, Zoghbi HY, Moseley AB, Rosenblatt HM, Belmont JW: Methylation of Hpall and Hhal sites near the polymorphic CAG repeat in the human androgen-receptor gene correlates with $\mathrm{X}$ chromosome inactivation. Am J Hum Genet 1992, 51:1229-1239

24. Gilliland DG, Blanchard KL, Levy J, Perrin S, Bunn HF: Clonality in myeloproliferative disorders: analysis by means of the polymerase chain reaction. Proc Natl Acad Sci USA 1991, 88:6848-6852

25. Vogelstein B, Fearon ER, Hamilton SR, Feinberg AP: Use of restriction fragment length polymorphisms to determine the clonal origin of human tumors. Science 1985, 227:642-645

26. Pan LX, Diss TC, Peng HZ, Norton AJ, Isaacson PG: Nodular lymphocyte predominance Hodgkin's disease: a monoclonal or polyclonal B-cell disorder? Blood 1996, 87:2428-2434

27. Sawada M, Azuma C, Hashimoto K, Noguchi S, Ozaki M, Saji F, Tanizawa O: Clonal analysis of human gynecologic cancers by means of the polymerase chain reaction. Int J Cancer 1994, $58: 492-496$

28. Sidransky D, Frost P, Von Eschenbach A, Oyasu R, Preisinger AC,
Vogelstein B: Clonal origin of bladder cancer. N Engl J Med 1992 , 326:737-740

29. Noguchi S, Motomura K, Inaji H, Imaoka S, Koyama H: Clonal analysis of human breast cancer by means of the polymerase chain reaction. Cancer Res 1992, 52:6594-6597

30. Barsky SH, Grossman DA, Ho J, Holmes EC: The multifocality of bronchioloalveolar lung carcinoma: evidence and implications of a multiclonal origin. Mod Pathol 1994, 7:633-640

31. Nettesheim P, Szakal AK: Morphogenesis of alveolar bronchiolization. Lab Invest 1972, 26:210-219

32. Colby TV, Koss MN, Travis WD. Morphologic diagnosis and heterogeneity of carcinoma of the lung. Atlas of Tumor Pathology: Tumors of the Lower Respiratory Tract, 3rd series, Fasc. 13. Washington DC, Armed Forces Institute of Pathology, 1995, pp 135-143

33. Kodama T, Biyajima S, Watanabe S, Shimosato Y: Morphometric study of adenocarcinomas and hyperplastic epithelial lesions in the peripheral lung. Am J Clin Pathol 1986, 85:146-151

34. Nomura S, Kaminishi M, Sugiyama K, Oohara T, Esumi H: Clonal analysis of isolated single fundic and pyloric gland of stomach using X-linked polymorphism. Biochem Biophys Res Commun 1996, 226: 385-390

35. Mutter GL, Boynton KA: PCR bias in amplification of androgen receptor alleles, a trinucleotide repeat marker used in clonality studies. Nucleic Acids Res 1995, 23:1411-1418

36. Noguchi S, Aihara T, Koyama H, Motomura K, Inaji H, Imaoka S: Discrimination between multicentric and multifocal carcinomas of the breast through clonal analysis. Cancer 1994, 74:872-877

37. Murry CE, Gipaya CT, Bartosek T, Benditt EP, Schwartz SM: Monoclonality of smooth muscle cells in human atherosclerosis. Am J Pathol 1997, 151:697-705

38. Noguchi S, Motomura K, Inaji H, Imaoka S, Koyama H: Differentiation of primary and secondary breast cancer with clonal analysis. Surgery 1994, 115:458-462

39. Noguchi M, Maezawa N, Nakanishi $Y$, Matsuno $Y$, Shimosato $Y$, Hirohashi S: Application of the p53 gene mutation pattern for differential diagnosis of primary versus metastatic lung carcinomas. Diagn Mol Pathol 1993, 2:29-35

40. Noguchi M, Furuya S, Takeuchi T, Hirohashi S: Modified formalin and methanol fixation methods for molecular biological and morphological analyses. Pathol Int 1997, 47:685-691 